\title{
Structural and topological analysis of electric energy consumption of municipalities as the basis for the development of the regional energy efficiency strategy
}

\author{
S. V. Fedorova \& P. Yu. Khudyakov \\ Ural Power Institute, Ural Federal University, Russia
}

\begin{abstract}
The amplifying polarization of the development of municipalities, the concentration of megalopolises' development possibilities and the decrease of potential of the development of small territories make it urgent to create tools for monitoring, estimating and forecasting of the electric energy consumption in order to develop the regional energy efficiency strategy, which will facilitate the sustainable development of municipalities.

The paper gives the authors' definition of the energy efficiency of municipal units as the degree of real electric energy consumption compliance with the indicators of efficient energy consumption, along with providing comfortable habitation for the residents. The target indicators of municipal units' energy efficiency can be achieved by the efficient consumption and usage of electric energy.
\end{abstract}

The authors carried out structural and topological analysis of electric energy consumption municipal units of the region, based on the sustainable development methodology. The formulated S-distributions of electric energy consumption of municipal units revealed a self-organization regularities in the region, which were reflected in municipal units' three-zone rating, formulated in accordance with electric energy consumption intensity.

The results of the structural and topological analysis of electric energy consumption in absolute indicators and competitive speed indexes (intensity of electric energy consumption) are the basis for electric energy consumption forecasting of the region, as an integral structure formed by municipal units.

Keywords: structural and topological analysis, sustainable development, energy efficiency strategy of municipalities. 


\section{Introduction}

Nowadays, the process of polarization of a region's municipality development is revealed in the concentration of development possibilities of a megalopolis on the one hand and the decrease in the potential of small territories' development on the other.

According to the Regional Ministry of Economic Affairs the estimation of social, demographic, economic and investment potential of the Sverdlovsk Region shows, that $42.3 \%$ of municipalities have low growth rates, $67 \%$ of which are municipalities with low-level infrastructure and resource endowment.

There are 1019 settlements in the territory; 325 of them have gas infrastructure, 30 of them are not electrified. The sustainable development of the region requires the development of the corresponding tools, providing for the development of its constituent municipalities.

The structural and topological analysis of the municipalities' electric energy consumption in the period of the previous 5-7 years reflects the non-uniformity of their development, allows to estimate the stability of the territories from the viewpoint of evolutionary processes taking place in complex structures in the competitive struggle for resources [1-5].

The development of the regional energy efficiency strategy is closely connected with the achievement of sustainable development, economy ecologization, environmental protection and, thus, with the state of environmental comfort of the citizens [6].

\section{Sustainable development and region energy efficiency}

According to the United Nations Organization's documents devoted to the sustainable development of cities: a stable city is a city "in which achievements in the public, economic and physical development are constant; which is constantly provided by natural resources and supports long-term safety of its inhabitants, including safety from natural disasters" [7].

The evolutional character of the sustainable development of a territory, which leads to the ability not only to raise the standard of well-being of the territory's citizens, but also to increase its potential for the future generations, is emphasized in Ikonnikova's definition [8].

Hajrullov in his works states that the sustainable development of a region implies the satisfaction of the vital needs of the living people and the future generations as well [9].

Kuvshinov understands the sustainable development of a territory as a targeted process of municipalities' social and economic systems management, providing the stability of the links, elements and system structure as a whole with the aim of raising the level of life quality of the population, simultaneously balancing the environment.

He emphasizes the definition of a higher form of the stable organization of the system, capable to develop steadily, self-regulate, self-govern, self-improve, making maximum use of inner and extra resources [10]. 
Fufaev reveals the concept of the system stability not only from the point of coming back to its settled state after various disturbances, but also from the point of its parameters optimization and structure maintenance [3].

The development of the regional energy efficiency strategy is closely connected with the achievement of sustainable development and, thus, with the state of environmental comfort of the citizens.

Taking into account the given definitions, we can formulate the definition of municipalities' energy efficiency as the degree of real electric energy consumption compliance with the indicators of efficient energy consumption, allowing for the comfortable habitation of the citizens.

The sustainable development of a region requires specific tools, facilitating the development of its constituent municipalities. Therefore, the factors influencing the territory's energy efficiency were revealed in the context of comfortable habitation indicators.

The analysis of existing research works in the sphere of regional and municipal energy efficiency estimation, competitiveness, cities investment prospects, as well as monitoring of 22 municipal energy saving programs, brings us to the following conclusions $[1,5-12]$ :

1. Development of energy efficiency indicators of the majority of municipal programs has formalized character.

2. The processes, connected with structural self-organization of municipalities in energy efficiency estimation techniques are not considered.

3. There is no structural and topological electrical energy consumption analysis, which can be considered as an indicator of territory development stability.

4. In ratings definition techniques of competitiveness, investment prospects, life quality energy efficiency is often considered as one of the indicators, or only its economic or ecological component is reflected.

Thus, the development of energy efficiency strategy methodology on the basis of the multifactorial estimation, taking into account the level of environmental comfort for citizens, evolutionary development of the territory, structural and topological analysis of municipalities' electric energy consumption, makes the most sense for energy efficiency estimation.

As a result, we have identified eight integral factors with corresponding comfortable environment state indexes, affecting energy efficiency of the territory, to include them into evaluation algorithm (tab. 1).

The weight factors were determined by expert assessments method for each indicators group.

Integral evaluation of environment comfort indexes for each of the municipalities will give the possibility to carry out their analysis and to prepare corresponding proposals for energy-saving and efficiency programs improvement within the strategy under consideration. The solution of the optimization problem of comfortable living environment function maximization according to the given constraints makes it possible to create a model of city's energy efficiency management. 
410 Energy Production and Management in the 21st Century, Vol. 1

Table 1: $\quad$ Factors influencing the energy efficiency of the territory.

\begin{tabular}{|c|c|c|}
\hline Factor & Type & Indicators \\
\hline$X_{1}$ & Structural & $\begin{array}{l}\text { - structural dynamics of goods and } \\
\text { services development; } \\
\text { - dynamics of production } \\
\text { development in comparison with } \\
\text { other organizations; } \\
\text { - dynamics of energy production } \\
\text { intensity; }\end{array}$ \\
\hline$X_{2}$ & Infrastructural & $\begin{array}{l}\text { - dynamics of service-providing } \\
\text { organizations development } \\
\text { (education, health, culture); }\end{array}$ \\
\hline$X_{3}$ & Ecological & - dynamics of emissions reduction; \\
\hline$X_{4}$ & $\begin{array}{l}\text { Natural and climatic, } \\
\text { geographical }\end{array}$ & $\begin{array}{l}\text { - the presence of local fuel sources; } \\
\text { - the distance between the consumer } \\
\text { and the energy sources; } \\
\text { - Renewable energy potential; }\end{array}$ \\
\hline$X_{5}$ & Social & $\begin{array}{l}\text { - the population growth; } \\
\text { - dynamics of employable age } \\
\text { population; } \\
\text { - presence of working staff innovative } \\
\text { potential; } \\
\text { - lodging purchase availability; }\end{array}$ \\
\hline$X_{6}$ & Economic & $\begin{array}{l}\text { - share of the unprofitable enterprises; } \\
\text { - territory budget sufficiency; } \\
\text { - dynamics of tariffs for energy } \\
\text { sources; } \\
\text { - dynamics of large and average } \\
\text { organizations investment in fixed } \\
\text { capital; }\end{array}$ \\
\hline$X_{7}$ & Energetic & $\begin{array}{l}\text { - structural and topological dynamics } \\
\text { of electrical energy consumption; } \\
\text { - dynamics of electrical energy losses } \\
\text { in the electrical networks; } \\
\text { - dynamics of fuel utilization factor; }\end{array}$ \\
\hline$X_{8}$ & Cultural & $\begin{array}{l}\text { - dynamics of energy efficient } \\
\text { products demand; } \\
\text { - the presence of educational centers, } \\
\text { energy saving and energy efficiency } \\
\text { exhibition zones and centers. }\end{array}$ \\
\hline
\end{tabular}




\section{Structural and topological analysis of municipalities' electric energy consumption}

The target indicators of municipal units' energy efficiency program can be achieved by the efficient consumption and usage of electric energy.

The authors carried out structural and topological analysis of electric energy consumption of 43 municipal units of the region, containing 2686 enterprises, within the 7-year time period, based on the sustainable development methodology.

Algorithm of the structural and topological analysis begins with the ranking analysis of region municipalities' electric energy consumption.

\subsection{Ranking analysis of region municipalities' electric energy consumption}

Our research is based on technocoenosis approach developed by Kudrin B.I. It is one of the possible methods to analyze and model large technical systems.

Identifying of regional enterprises' electric energy consumption trends as well as the analysis of rank distribution parameters are the basis of electric energy consumption management optimization, which makes it possible to forecast further development of electric energy complex of Sverdlovsk region more accurately and to assess its sustainability $[1,4,11]$.

Technocoenosis under consideration is referred to as "Sverdlovsk region enterprises", united in municipalities.

The rank of H-parameter distribution of electric energy consumption is formulated in the following coordinates: (Rank) against $W(r)$. Distribution is described by the following expression:

$$
W(r)=W_{1} / r^{\beta},
$$

where $r$ - object rank, $W_{1}-$ factor (maximum electric energy consumption of the object), $\beta$ - characteristic exponent $[2,11]$.

The cenological mathematical apparatus of hyperbolic H-distributions, connecting global evolutionism ideas with nongauss statistics, was firstly introduced by Kolmogorov [13].

One of the H-rank distributions obtained during 2005-2011 is presented in fig. 1 .

Characteristic exponent $\beta$ determines the steepness of the curve, and its value makes it possible to judge the technocoenosis optimality and efficiency in general (1).

It is theoretically proved and statistically confirmed that stable technocoenosis structure, described by H-rank distribution parameter, is characterized by the following: the first $10 \%$ of the units (the first decile) have 10 times greater resource than the last $10 \%$ of the units (the tenth decile) [4].

In relation to the Sverdlovsk area, as it can be seen from fig. 1, decile ratio of 10:1 is not satisfied (in fact $-8000: 1$ ), indicating insufficient growth of small municipalities. Characteristic exponent of $\mathrm{H}$-rank distribution for 2011 equals to $\beta=2.4$, that exceeds the predefined limits $0<\beta<1.5[1,2]$. 
The main reason is the large gap between the megalopolis's and small regional municipalities' development level. So it is necessary to assess megalopolis's development principles separately as it can be considered as individual technocoenosis and exclude it from the community of the municipalities during the analysis.

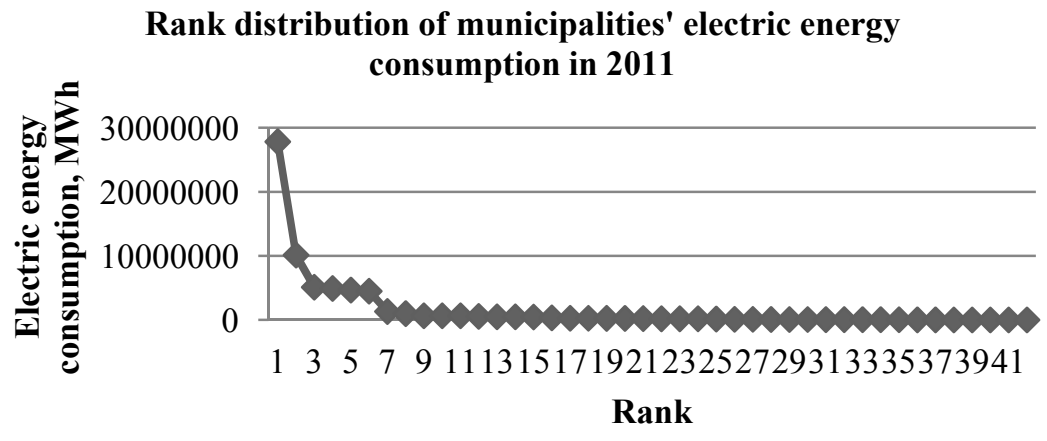

Figure 1: Rank distribution of electric energy consumption of Sverdlovsk region municipalities in 2011.

It is of strategic importance to strengthen the vector of small areas development to achieve sustainable development of the region.

Technocoenosis dynamics processes analysis is carried out by passing to structural and topological electric energy consumption dynamics assessment. It is performed by adding the third time-axis to the axes of rank distribution.

As result we obtain the set of stochastic trajectories of electric energy consumption indicators variation in time [3].

\subsection{Structural and topological dynamic of municipalities' electric energy consumption}

We have constructed structural and topological dynamics of municipalities' electric energy consumption for 5-7 years retrospective time horizon (fig. 2) without Yekaterinburg-city. The diagram illustrates municipalities' development unevenness [1-3], which gives the possibility to estimate stability of the territory from the perspective of evolutionary processes in complex structures, being in the competition for energy resources.

Significant changes in electric energy consumption during last seven years are observed in the municipalities with ferrous metallurgy enterprises, electric energy industry and chemical industry.

In some areas electric energy consumption has not decreased even during economic recession in 2009 , which proves their sustainable development. These include municipalities without significant drop in production.

The resulting surface is the basis for regional electric energy consumption forecasting. 


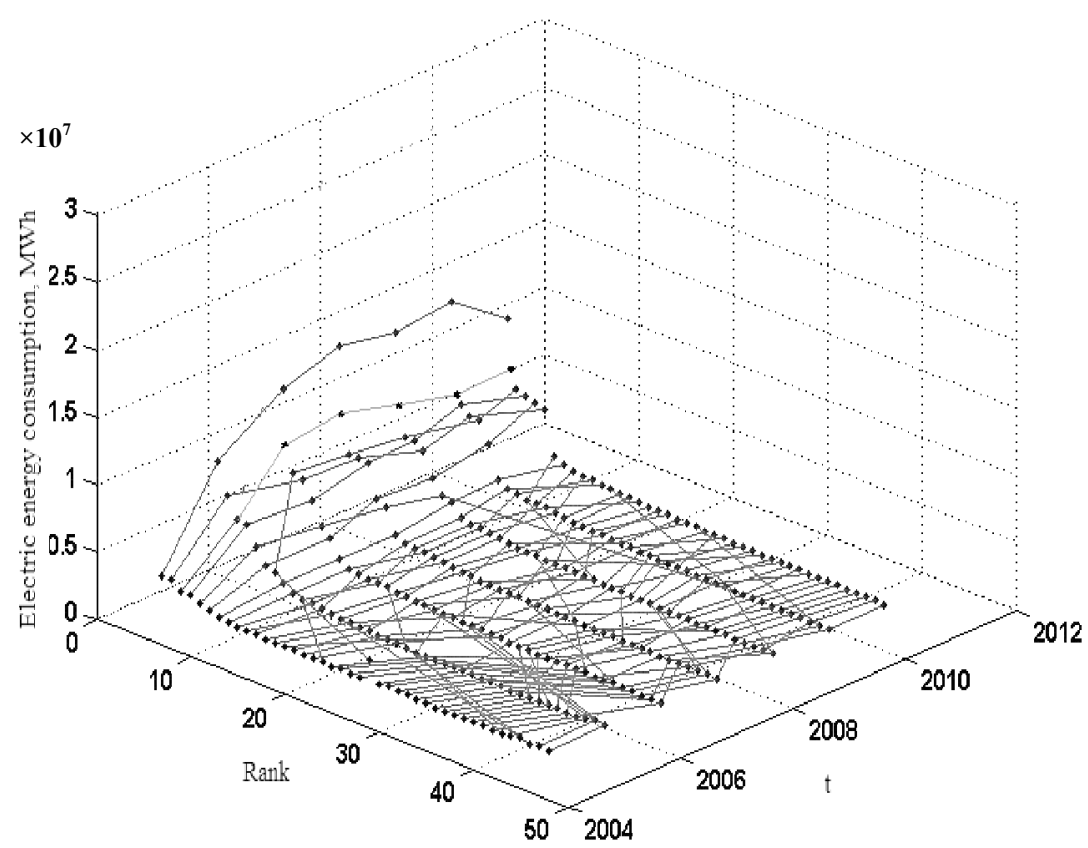

Figure 2: Structural and topological dynamics of Sverdlovsk area municipalities' electric energy consumption, 2005-2011.

\subsection{S-distribution of structural and topological electric energy consumption self-organization of municipalities in the region}

To perform structural and topological self-organization analysis at competitive rates in general for Sverdlovsk region municipalities we have constructed Sdistribution of competitive velocities (electric energy consumption intensities) of structural and topological self-organization (Speed - distribution) [3].

Rank trajectory of technocoenosis (municipality) individual element, plotted against time in coordinate system $r=f(t)$ projection, is an objective measure of the correlation between the element topological characteristics and the topological properties of other elements of technocoenosis.

To determine electric energy consumption intensity of each municipality, their rank-trajectories are estimated in accordance with the annual electric energy consumption values within the time-period under consideration. Constructed trajectories are applied as linear trends $[2,3]$.

Inclination angles of the linear trends (positive, negative, zero) serve as indicators of the electric energy consumption intensity or competitive rates, that give the possibility to assess municipalities' competitiveness (fig. 3).

Positive sign of the slope $(+\varphi)$ is assigned to technocoenosis elements, velocity vector of which is targeted at rank reduction (increase of electric energy consumption intensity), the negative one $(-\varphi)$ - at rank increase (lowering of electric energy consumption intensity). 


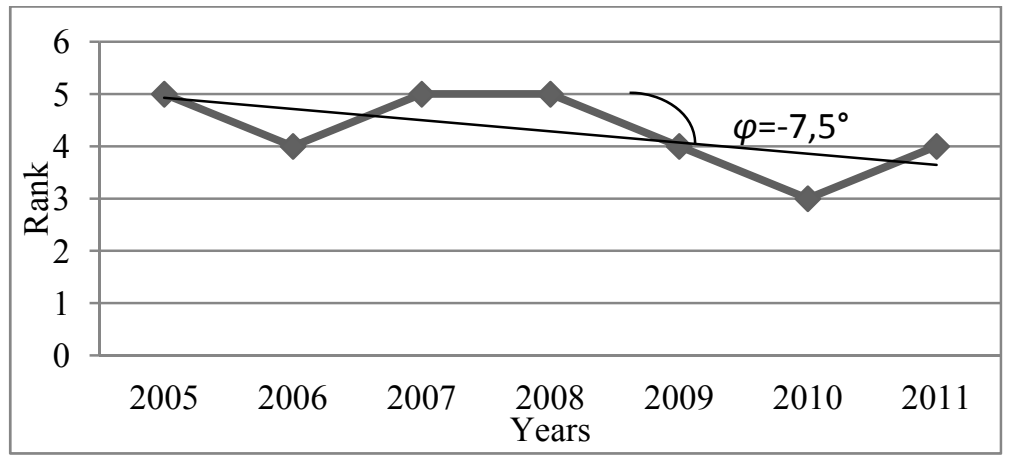

Figure 3: $\quad$ Ranking trajectory of the municipality № 30.

S-distribution of municipalities' electric energy consumption intensity revealed patterns of self-organization in the region, that resulted in municipalities consolidation into three zones of activities, depending on the electric energy consumption intensity (fig. 4).

The first zone includes municipalities with positive velocities, the second zone includes municipalities with negative velocities, and the third zone includes municipalities with low and zero ones.

Analysis of both S-distributions branches of the technocoenosis showed that they were equal in the number of objects with different signs (50:50), which corresponds to stable technocoenosis condition. Maximum velocities of the first elements from the positive and negative zones are almost equal $[3,4,13]$.

We have identified municipalities with zero angles (bifurcation points) and municipalities with angles close to zero, which makes it possible to determine sustainable development areas $(36,8,21,30,26,16,6,22,31,19)$, constituting a zone of stability and minimal risk. The development of these municipalities' enterprises is synchronized with technocoenosis in general.

The zone of high activity includes municipal units (the leading territories) with developing town-forming enterprises $(12,35,33,13,1,29,39,38,41,37$, $40,42)$, where the positive intensity of electric energy consumption is associated with the implementation of new production capacities, the development of territorial infrastructure and, consequently, the improvement of the comfortable living environment for residents.

Group of municipalities $(32,4,25,15,34,20,18,27,23,10,9,17,14,3,7$, $24,5)$ with low intensity of electric energy consumption (territories-outsiders) is characterized by instability of enterprises, reduced production, and closing businesses, which worsens the comfortable living environment for residents.

Thus, structural and topological dynamics of municipalities' electric energy consumption makes it possible to reveal the territory leaders that are resistant to external influences and territory-outsiders. The result provides us with the corresponding vector of energy efficiency strategy $[2,3]$. 


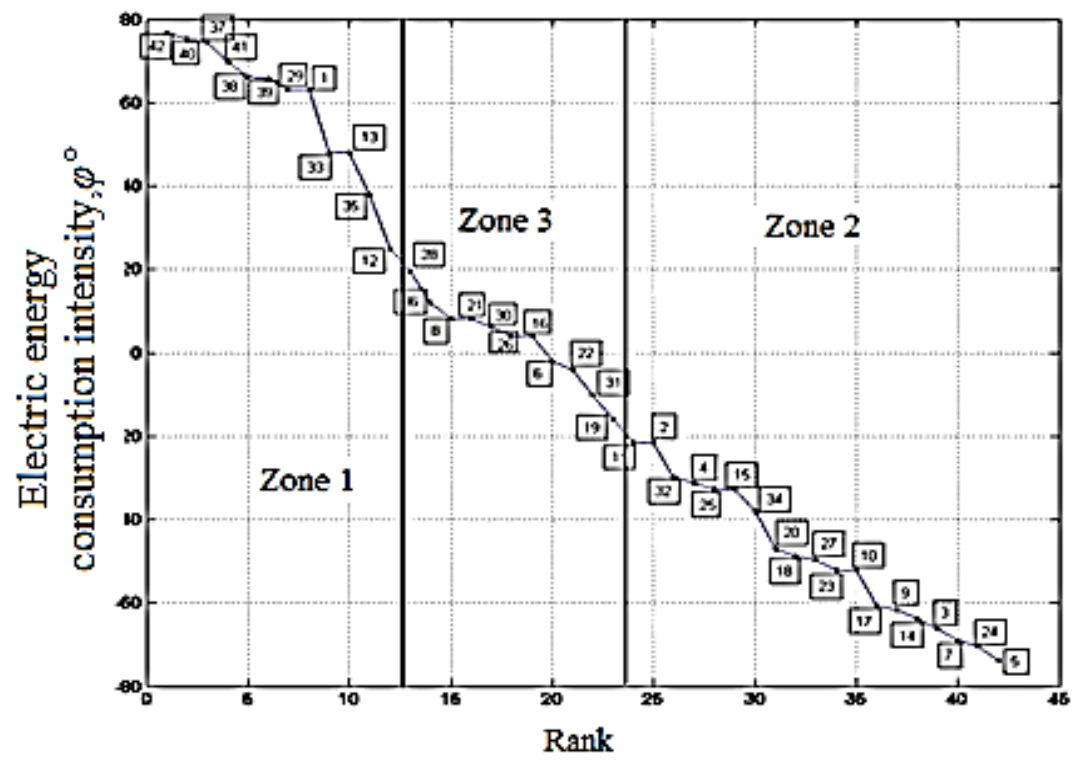

Figure 4: S-distribution of Sverdlovsk region municipalities' electric energy consumption intensity, 2005-2011.

Further, it is necessary to define comfortable living environment indicators and implement an integrated assessment of the comfortable environment for each of the municipalities according to the factors, influencing the energy efficiency, regarding areas of activity.

Optimization problem solution with respect to objective function of comfortable living environment maximization, given the scope of the zonal constraints, will provide sufficient data to construct a model of municipality energy efficiency management.

The membership in a certain zone is a starting point for energy efficiency strategy development for the corresponding group of territories (Zone 1 innovative strategy, Zone 3 - sustainable-developing strategy, Zone 2 - strategy "Transition city").

\section{Conclusion}

Structural and topological analysis of the municipalities' electric energy consumption in the region, carried out on the basis of technocenological approach allowed for regional enterprises electric energy consumption structure and dynamics estimation in three dimensions: time period, the level of electric energy consumption and its intensity.

To assess the energy efficiency of the region the authors propose the application of the integral indicator, reflecting the comfort of the living 
environment for the citizens, which depend on the set of factors, influencing energy efficiency.

The results of the structural and topological analysis of electric energy consumption in absolute indicators and competitive speed indexes (intensity of electric energy consumption) are the basis for electric energy consumption forecasting of the region as an integral structure formed by municipal units.

\section{References}

[1] Gnatyuk, V.I. The law of technical coenosises optimum construction: the computer monograph. Publishing house TGU - the center of system researches, 2005, 2011, http://gnatukvi.ru/ind.html.

[2] Fufaev, V.V. Structural and topological self-organizing of technical coenosises electric energy consumption S-distributions on examples of the region organizations, the branch enterprises and Russian regions. Cenological researches interdisciplinary. Release 43. Cenological researches. Technetics, pp. 14-26, 2010.

[3] Fufaev, V.V. Cenological definition of parameters of electric energy consumption, reliability, installation and repair of region enterprises electric equipment. Moscow: the center of system researches, 2000.

[4] Kudrin, B.I. Coenology. Technetics. Electrical / Electronic resource: http://www.kudrinbi.ru.

[5] Dmitriev, S.A., Kokin, S.E. Working out the policy of technical modernization of big cities' power supply on the basis of network condition estimation model. Proc. of the $9^{\text {th }}$ Int. Conf. of Environment and Electrical Engineering, EEEIC: Czech Republic, Prague, Code 81302, pp. 226-229, 16-19 May 2010.

[6] Bobylev, S.N., Zubarevich, N.V., Soloveva, S.V., Vlasov, Ju.S. Sustainable development: methodology and measurement techniques. Moscow: Economy, 2011.

[7] 17 Indicators of sustainable development: framework and methodologies, UN commission on Sustainable Development, New York, 2001.

[8] Ikonnikova, O.V. Fundamental approaches to concept definition «the Sustainable development of rural territories». Agriculture Economy, pp. 349-352, № 1 (41) 2012.

[9] Hajrullov, D.S. Sustainable region development as a basis of national economy safety. Proc. of the $4^{\text {th }}$ All-Russia scientific conf. Information technologies in system of social and economic safety of Russia and its regions. Kazan, KFU, pp. 41-49, on April, 23-26 2012.

[10] Kuvshinov, M.A. Management concept of a sustainable development of municipalities' social and economic system. The young scientist, pp. 8691, №7 T.1 2011.

[11] Pazderin, A.V., Egorov, A.O., Eroshenko, S.A. The energy meters allocation in electric systems on the basis of observability theory. Proc. of the $9^{\text {th }}$ Int. Conf. of Environment and Electrical Engineering, EEEIC: Czech Republic, Prague, Code 81302, pp. 167-170, 16-19 May, 2010. 
[12] Mogilenko, A.V., Pavljuchenko, D.A. Important aspects of monitoring and analysis. News electrical engineers, pp. 9-15, №4 (70) 2011.

[13] Kolmogorov, A.N. Basic concepts of probability theory, 1974. 